\title{
Essentials of Library Manpower Budgeting
}

\begin{abstract}
Libraries in state-supported institutions find their quest for legislated funds increasingly competitive. New devices are needed to substantiate their claims for higher budgets. To meet one of these needs, the State University of New York has prepared a library manpower budget formula for its several campuses by developing weighted standard times for accomplishing library operations in various kinds of institutions and correlated with various library characteristics. The rationale and methodology of the formula are described. This paper was read to the New York Library Association, College and University Section, in Rochester, on May 3, 1969.
\end{abstract}

B UdGETING FOR HIGHER EDUCATION in state-supported institutions presents unique problems of policy and methodology. State institutions are dependent on the largess of the legislative body for the bulk of their financial support, and like other state supported public programs, such as welfare and health, must articulate their needs both in terms of academic programs and in a format understood by the governmental budget office.

The need for state budget support has been increasing exponentially since 1945. Larger enrollments, expanded functions, inflation, and broadening of the educational objectives of individual institutions are typically part of the management dilemma of harassed university administrators. Legislators find their involvement with allocation of limited resources, including the exploding higher education needs, a frustrating one. Their concern has typically been ex-

Mr. Fairholm is Principal Budget Examiner in the New York State Division of the Budget, Albany. pressed in terms of requests for more detailed "justification" of academic budgets, and to more precise, quantifiable, objective data and methodology.

Library administrators have been caught in this squeeze. Often they have been hard-pressed to produce information in quantitative terms that at the same time reflected accurately their operations, activities, and needs. The quantitative data they have produced has led to the development of formulas of various kinds to consolidate objective measures of performance. Along with benefit-cost analysis and related techniques, these formulas provide both university administrators and state legislatures with a common language and a common knowledge-base upon which to negotiate needed program budgets in an ever-increasing competition for limited resources.

A formula basis for budgeting in university libraries has many advantages. Formulas are simple and direct, and they emphasize critical measures and provide an objective method of relating one campus to others within a state higher-edu- 
cation complex. They reduce the bulk of paper needed, focus on key issues, facilitate comparisons from campus to campus and from year to year, and reduce the element of risk in decision-making (risk of making mistakes and risk of producing conflict among competing elements).

These advantages, however, are relevant only insofar as the formula adopted reflects accurately the real-world situation at campuses. The "multiversity" is becoming the norm in state-supported higher education, and differences among campuses in terms of basic descriptive characteristics must be built into the formula "model" if it is to be of use in a complex multiinstitutional university. Enrollment differences in the academic program-mix, graduate and honors programs, special research goals, and other descriptive characteristics of individual campuses must be considered and properly accounted for in the development and use of budget formulas for higher education libraries. The advantages of a formula that does account for these variables are obvious.

This discussion will focus on a formula basis for library manpower budgeting. Library manpower can probably be correlated to quantitative measures more easily than any other factor of library operation. Especially in large-scale, multicampus academic institutions, library staffing presents problems of rationalization and equality that require some references to "standards" or formulas, to some common ground upon which valid decisions and comparisons can be made. When standard-setting authorities in the university fail to set standards in quantitative terms, budgeting authorities are compelled to do so. The resulting standards usually have the virtue of simplicity, but they often fail to meet the real needs of both the institution and the central management.

A unique joint effort at standard-set- ting for library staff has been conducted by the New York State Division of the Budget and the State University System (SUNY). Formulas to assure adequate staffing for the burgeoning libraries were seen as the logical solution to this problem. However, formulas had to be developed which recognized widely different organizational and procedural characteristics of over thirty campus libraries, and which accommodated the decentralized management philosophy of SUNY.

As a first step, available rules of thumb and formulas developed for use in other libraries in the United States were analyzed. ${ }^{1}$ They were found to be unacceptable for New York State purposes because of the unique place of libraries in the rapid growth phase of SUNY libraries. Accordingly, an attempt was made to develop formulas which accommodated the key variables of libraries in the system. The result, while admittedly not the last word in formulabased library manpower forecasting, provides a quantifiable basis that could resolve many key staffing decisions in this area.

\section{Essential Aspects}

Essentially the formula which was developed relies on a correlation of work effort in libraries to five forecastable characteristics (or "descriptors") of an academic library. These five descriptors include holdings, acquisitions, full-time equivalent users, headcount students, and full-time equivalent faculty and selected professional staff of the university. Work effort was defined by reference to an abstract prescriptive model that utilized essential library functions and quantified output in a series of "standard times" related to each unit of the five characteristics. Totals of these five characteristics and their standard output units can be forecasted for planning and budgetary purposes and to- 
gether are indicative of library activity.

The library descriptors reflect two characteristics-holdings and clientele. An academic library's manpower requirements are directly related to the size, character, educational goals and mission of the institution it serves. These institutional characteristics are reflected in several quantitative factors that describe the library:

1. Holdings - In any library, the size of the collection directly affects staff. Stated simply, large libraries require more staff to perform tasks directly related to books on shelves than small libraries.

2. Acquisitions-Acquisition of new materials has a direct impact on the volume of technical services. The larger the number of volumes added, the larger the staff requirements.

The larger the potential clientele of the library, the more staff is required to service it. In academic libraries, users are defined as students, faculty, staff, and community. Users affect the library on three levels.

3. FTE Users-The total student populations of the institution served by the library (including extension programs) equated to full-time equivalent students (FTE) plus the fulltime equivalent faculty users constitute a user category to which significant library functions are directly related.

4. Headcount-The total number of actual students enrolled in an institution affects the extent of library services needed. Whether a student takes one course or a full academic course load, his potential use of certain library services is the same.

5. Faculty and Staff-Often the academic faculty and the university professional-level staff are ignored as potential users of the libraries resources. These individuals actually place identifiably special loads on the resources of the library and should be specially considered in any accurate description of library users. Implied in these characteristics are the academic and program faculty, and the scope of curriculum and degree programs, which help describe the institution itself and, therefore, affect the library.

For comparative purposes, these five characteristics most accurately describe the nature of the library. The character of the holdings may also be important; but, except for certain obvious situations (foreign language collections, for example), size of holdings is a more realistic basis for comparison of library manpower needs. ${ }^{2}$ Also, the bulk of most collections is represented by traditional holdings. More importantly, it was found that each of the common library functions was directly relatable to one of these five characteristics.

Reference has been made to the relationship of the descriptors and the common functions of libraries. The functions of library staff (both professional and nonprofessional) that make up the business of librarianship were synthesized in this study and a listing was developed that represents the central nature of library activity. Since this listing emphasized what must be done in academic libraries, rather than how it is done, it was possible to ignore the difference in organizations and procedures of individual libraries and thus deal with the heart of librarianship, not its outward technique.

In order to produce this kind of a listing of intrinsic library functions, a model of library operations was first developed. This model, an abstract representation of library operations, focused on the essential functions and responsibilities of libraries, and was displayed in a series of linear flow diagrams. These flow diagrams related activities and tasks necessary to achieve certain events or conditions conducive to processing 
books or responding to user demands. These diagrams were validated by internal checks of consistency and logic and by a panel of senior library professionals. $^{3}$

\section{Units OF MEAsure}

Once developed and validated, the list of common library functions was used to prepare a list of 59 units of measure of library activity. These units of measure, reproduced in column 1 of Table 1 , are the countable output of library activity and effectively clump the common functions into countable units.

There are fewer units of measure than there are library functions. This is because completion of one unit of measure may require library staff to perform several functions. Thus, the units of measure actually summarize related library functions. For example, when we say it takes $x$ minutes to charge out a book, we really mean it takes a total of $x$ minutes to charge out the book, place a slip in the circulation files, and, if necessary, renew the book and refile the slip. The units of measure then represent clusters of individual functions.

\section{UnIt STANDARDS}

Using the 59 units of measure as a framework, a median time (in minutes) to perform each unit of measure was developed statistically through a questionnaire and interviews. In order to relate similar facilities and make the statistics more useful, the libraries in the sample were broken down into three classes, corresponding to the different missions of SUNY libraries, i.e., universities, liberal arts colleges, and agricultural and technical colleges. ${ }^{4}$ Separate standards were developed for each class.

To refine further the statistical data collected, a series of workshops of librarian specialists was held in which they were asked:

1. to refine the list of typical library functions and the units of measurable output;

2. to develop standard times to perform these key work load units of measure;

3. to modify, as necessary, these standard times, taking into consideration factors that go to make up a good library operation.

Throughout the workshops the emphasis was on producing high quality standards that reflect good librarianship and not merely "average current performance," that may or may not reflect good practice.

The statistical bases were used as a check against the standards and to relate developed standard times to current real-world situations in the libraries. As a result of these workshops, Unit Standard Times were produced which reflect (for SUNY at this stage of its development) the standard of performance of library manpower in terms of staff time (in minutes) per unit of output ( see column 3 in Table 1). Separate standards were produced for each of the 59 units of measure for each classification of library.

\section{Application Factors}

It will be readily seen that Unit Standards alone are not sufficient for forecasting library staff needs. While they provide an effective measure of individual performance of a given task, they do not reflect total manpower needs since not all functions are performed for every book or for every potential user. The relationship between functions performed and manpower needs was mathematically derived by relating actual performance of specific functions to one or another of the five key characteristics isolated previously (i.e., holdings, acquisitions, FTE users, headcount, and faculty and staff). Common library functions were grouped according to these basic characteristics and a mathematical fac- 
tor derived by dividing the appropriate output data (by class) by the appropriate key characteristics. Data used came from the sample of eleven libraries for which data were collected. The resultant factor represents the frequency with which a given function is performed on an average unit of each of these five characteristics. Column 2 of Table 1 lists these applications factors.

\section{Weighted Standard Times}

Once the standard time for performing a given function had been determined and the frequency of its application in the library to a given characteristic had been established, simple multiplication produced a "weighted standard time," or the average time required to perform the function (or cluster of functions) for each unit of each

TABLE I

Weighted Standard Times CLASS I (Ag. and Tech.) LIBRARIES

\begin{tabular}{lllll}
\hline \hline $\begin{array}{l}\text { (Column 1) } \\
\text { Units of Measure }\end{array}$ & Unit & $\begin{array}{c}\text { (Column 4) } \\
\text { Weighted }\end{array}$ & $\begin{array}{c}\text { Column 2) } \\
\text { Application } \\
\text { Factor }\end{array}$ & $\begin{array}{c}\text { Standard Times } \\
\text { (Ctandard Times } \\
\text { (Min.) }\end{array}$
\end{tabular}

Technical Services Standards-Based on Volumes Added

$\begin{array}{llrrr}\text { Selection of monographs \& sets } & \text { Titles } & .759 & 3.0 & 2.277 \\ \text { Selection of series } & \text { Titles } & .074 & 5.6 & .414 \\ \text { Search of holdings } & \text { Searches } & 1.494 & 3.0 & 4.482 \\ \text { Typing of cards } & \text { Number typed } & 5.000 & 3.0 & 15.000 \\ \text { Typing of add-ons } & \text { Add-ons } & .060 & 2.4 & .144 \\ \text { Typing of cross-references } & \text { Cross-references } & .100 & 3.0 & .300 \\ \text { Revision of cards } & \text { Titles } & .100 & 2.4 & .240 \\ & & \text { Total Weighted Time } & 120.348 \text { min. }\end{array}$

\begin{tabular}{|c|c|c|c|c|}
\hline Inventory & Volumes & .906 & 1.2 & \\
\hline Binding & Volumes & .015 & 18.3 & .274 \\
\hline $\begin{array}{l}\text { Withdrawal of materials } \\
\text { from collection }\end{array}$ & Volumes & $\begin{array}{r}.017 \\
\text { Total }\end{array}$ & $\begin{array}{l}15.0 \\
\text { Time }\end{array}$ & $\frac{.255}{3.627}$ \\
\hline
\end{tabular}

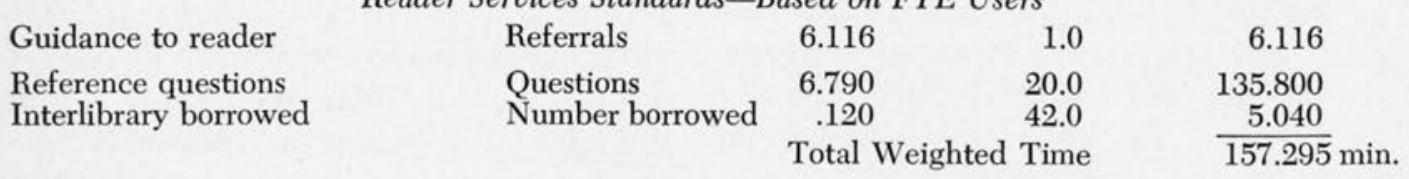

\begin{tabular}{lllcc} 
Charge-outs of materials & Volume & 6.993 & 2.0 & 13.986 \\
Return of materials & Volumes received & 9.154 & 4.2 & 38.446 \\
Preparation of overdue notices & Overdues & 1.141 & 7.2 & 8.215 \\
\cline { 2 - 4 } & & Total Weighted Time & & $\mathbf{6 0 . 6 4 7}$ min.
\end{tabular}

Reader Services Standards-Based on Faculty \& Staff

\begin{tabular}{llrrr} 
Abstract prepared & Abstracts & .050 & 15.0 & \multicolumn{1}{c}{.750} \\
Bibliographies prepared & Bibliographies & .200 & 450.0 & 90.000 \\
Interlibrary loans & Number loaned & .250 & 22.0 & 5.500 \\
& & \multicolumn{1}{c}{ Total Weighted Time } & \multicolumn{1}{c}{ Th.250 min. } \\
& &
\end{tabular}


of the five key characteristics. The total of all of these average times (i.e., Weighted Standard Times) indicates the staff time required for each unit for each of the five basic library descriptive characteristics. These totals, when multiplied by the forecast quantities of each characteristic for a given year, indicate the total staff time required for that library to perform routine library operations (see Column 4, Table 1).

Table 1 summarizes this data for Agricultural and Technical Colleges within the SUNY System in 1968. In column 1 the subdivisions list the units of measure isolated from all library functions. Column 2 shows the application factor or the average frequency of performance of a given unit of measure within SUNY libraries. Column 3 carries the unit standard time or the established time required to perform each unit of measure and column 4 has the weighted standard time or the average staff time required to perform each unit of measure in terms of each of the five key characteristics of a library. These totals constitute the standard requirement for library manpower for each increment of the five characteristics. Thus, for each unit of holdings, acquisitions, weighted users, head count, students and faculty and staff forecast by a library, the total staff time (in minutes) is shown as required to properly staff the basic functions of that library.

\section{Administration}

To this point library management has been left out of the data collected as a basis for the standard times. Administrative overhead for the total library has been considered separately. A percentage factor was developed from the statistical data and modified by the workshops to produce a management factor (or a manpower percentage ratio) for each class of library, i.e., I, university; II, liberal arts college; and III, agricultural and technical college. These administrative overhead rates are included in Table 2.

\section{TABLE 2}

Administration Standards-Based ON Percent of Technical Service and Reader Service Trmes by Classification

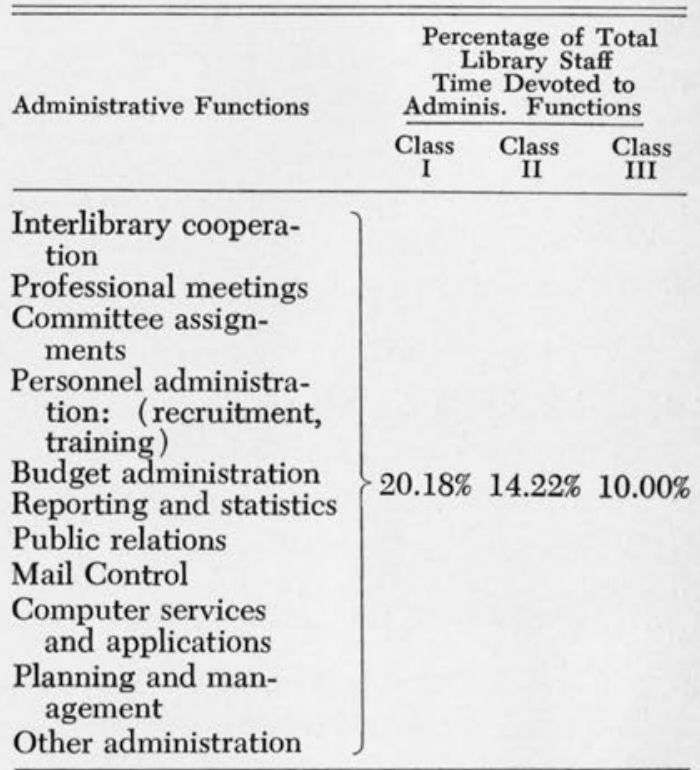

\section{Formula}

A simple formula has been created to relate this quantitative data in a meaningful way, and to facilitate budget forecasting for library staff. This formula will produce a figure that represents the total staff needs of a library for routine performance of library functions. The figure includes temporary services, staff, student assistants, and other staff members. The formula involves four steps.

\section{Technical Service Man-Year Require- ments $($ TS $)=$ $\mathrm{Aa}+\mathrm{Bb}$}

2. Reader Services Man-Year Requirements $(\mathrm{RS})=\quad \begin{gathered}\mathrm{Cc}+\mathrm{Dd}+\mathrm{Ee} \\ 96,000 \text { min. }\end{gathered}$ 
Total Weighted Standard Times

Where:

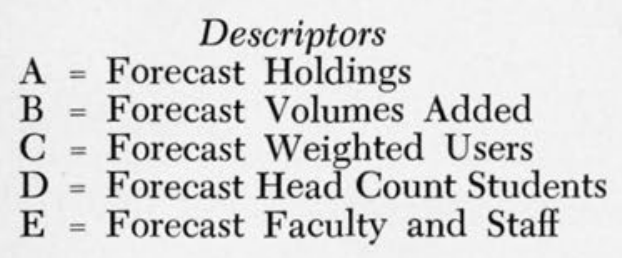

Where:

$\mathrm{X}=\%$ of TS \& RS STAFF Required for Administration

\begin{tabular}{rrr} 
& Class & \multicolumn{1}{c}{ Class } \\
I & \multicolumn{1}{c}{ II } \\
$\mathrm{a}=$ & 3.627 & 2.768 \\
$\mathrm{~b}=120.348$ & 120.831 \\
$\mathrm{c}=157.205$ & 120.308 \\
$\mathrm{~d}=$ & 60.647 & 139.214 \\
$\mathrm{e}=$ & 96.250 & 148.156
\end{tabular}

Class

III

2.437

142.258

165.167

207.517

174.174

\section{And Where:}

Number of minutes per man-year $=96,000$

(one man-year $=1,600$ hours $\times 60 \mathrm{~min} .=96,000 \mathrm{~min}$. $)$

3. Administration Man-Year Requirements $($ Adm $)=\mathrm{S}(\mathrm{TS}+\mathrm{RS})$

4. Total Library Man-Year Requirements $=$ TS + RS + Adm

\section{Limitations of the Formula}

It must be kept in mind that the formula represents staff needs for routine continuing library functions and not necessarily for the total activity of a library. As with any standard or formula methodology, this method of determining library manpower is useful only for those operations common to all libraries in the SUNY system. Unique features of an individual library must be considered separately from the formula.

Analysis will show that a few library operations have been omitted from the units of measure. Unique physical characteristics of the individual library and special programs of the library or the academic institution also affect library operations and therefore staff needs. These factors, described in more detail below, may require staff in addition to the formula computations. Nevertheless the formula was formed to reflect 85 to
95 percent of all library functions in SUNY and therefore provides a valuable and highly efficient tool for both analysis and comparison of libraries.

\section{SPECIAL FunCtions}

A few library functions do not relate directly to any one of the five key characteristics identified. They should, of course, be reflected in final requests for library manpower, but they must be justified outside of the formula technique. Some of these functions are common to all or most libraries while others are found in only one or a few institutions. Examples include: machine maintenance and operation, reproduction of general materials, selection of audiovisual materials, and security guard functions.

Unique and unusual physical characteristics of the environment may have an impact on library manpower needs. Factors which may require manpower beyond mere output levels are: several manned service points on different floors or in different buildings, branch or divisional libraries, and unusual or extensive hours of opening. ${ }^{5}$

Special programs of the library may 
require staff beyond the formula levels. These include: responsibility for audiovisual materials, special collections, and special research facilities.

The academic programs of the parent institution generate activities in academic libraries. Unusual programs and programs not found in other institutions may occasionally generate an unusual library manpower need. Among those to be considered are: extraordinary foreign language/subject matter programs and unusual research programs.

These unique or extraordinary circumstances may require separate justification, and when approved will necessitate increases in the formula staffing patterns. The flexibility thus assured protects individual libraries from a strict uniformity of staff that would stifle effective response to special and evolving situations both in librarianship and in the parent institution. Given this ability to deviate from formula standards, the standards themselves become more meaningful as a tool in library manpower determinations for higher education in the twentieth century.

The library is both an educational institution and a business operation. Management of the library must include evaluation of performance, the fulfillment of responsibilities, the accomplishment of purposes, the effective use of available resources, and the attainment of long-range objectives. These management activities must be interwoven in the constant process of serving the reference and research needs of the university. A formula-based realistic and flexible manpower forecasting system such as the one described here facilitates both academic and management goals in the library and within the total university complex.

\section{REFERENCES}

1. Examples of these rules of thumb include the American Library Association "standard" of budgeting for libraries as "five percent" of the total university budget. More specific rules of thumb for staffing had been used in certain areas of library operation. For example: a cataloger can process approximately 800 850 books per year. While they may be pertinent to a specific library or case in point, there is no justification, statistical basis or other rationale, that would support or substantiate their use in the SUNY library system or elsewhere.

2. A few library functions, while common to most libraries, showed no direct correlation with one of the five key characteristics. (Reproduction of general materials is an example.) These library tasks are excluded from the formula and must be included as a separate treatment of any unique aspects of the total collection.

3. The Chancellor's Advisory Library Committee reviewed and modified early drafts of these models. Throughout the study, librarian specialists participated by completing questionnaires, discussing their operations with the team, and attending workshops.

4. Library studies were analyzed according to ten descriptive characteristics: holdings, acquisitions, students, total users, faculty, academic programs, ILL materials borrowed, ILL materials loaned, bibliography preparation, and circulation rates. When the characteristics for each library were arranged in rank order, they clustered into three groups that reinforced and verified the 
present groupings of SUNY libraries according to institutional class-i.e., agricultural and technical colleges, liberal arts colleges, and university centers.

5. Under the formula a certain level of manpower can be established based on output or productivity of library staff. Conditions like those shown may require an additional segment of library staff time merely to man an open station. The incremental difference here must be computed in addition to the formula. For example, a reference station may require, on the basis of output forecasts, five man-years. The policy on hours of opening mandates that the reference desk be manned for a total of six man-years of time. The one-man-year differential is required on the basis of the policy of hours of opening, not on work load, and should be justified accordingly. 